\title{
Heart failure with preserved ejection fraction: A review of clinical status and meta-analysis of diagnosis by myocardial strain and effect of medication on mortality and hospitalization
}

\author{
Aref Albakri* \\ St-Marien hospital Bonn Venusberg, Department of internal medicine, Bonn, Germany
}

\begin{abstract}
Heart failure (HF)-related morbidity, mortality and health care burden remains unacceptably high, and with a rapidly increasing prevalence, the burden will increase substantially over the next few decades. Strongly associated with most of the increasing prevalence is an expanding population of $\mathrm{HF}$ patients with preserved ejection fraction (HFpEF), mostly precipitated or aggravated by a rapid increase in lifestyle and/or genetic conditions particularly hypertension, obesity and metabolic syndromes. Despite significant advances in therapies for $\mathrm{HF}$ with reduced ejection fraction (HFrEF), prognostic and clinical outcomes for $\mathrm{HFpEF}$ remain ominous. The paucity of research evidence supporting HFpEF therapies underscores the fundamental differences between $\mathrm{HFpEF}$ and $\mathrm{HFrEF}$ phenotypes of HF. The present review and meta-analysis summarizes the current understanding of the pathophysiology, diagnostic and therapeutic strategies to improve the current clinical management approaches.
\end{abstract}

\section{Introduction}

Heart failure affects about 26 million people worldwide and causes more than one million hospital admissions each year in the United States and Europe [1]. Therapeutic outcomes for ambulatory HFrEF have remarkably improved due to improvements of multiple evidencebased drug and device therapies. However, post-discharge mortality and re-admission rates for hospitalized HF remains unacceptably high and have not changed over the last two decades [2]. The proportion of patients classified as HFpEF continues to grow and may exceed HFrEF in a few years. The growth has serious clinical implications on effective clinical management of HF since HFpEF has poor characterization and lacks specific evidence-based therapies [3-5]. Attempts to deploy therapy with proven efficacy in HFrEF to HFpEF patients have been less successful [6-8]. Early research centered on diastolic dysfunction in pathophysiology of HFpEF but recent studies have revealed the contribution of multiple non-diastolic abnormalities [9]. In this review, etiopathogenic, diagnostic, and clinical trials are reviewed, along with meta-analysis of current diagnosis and clinical management.

\section{History, definition, epidemiology and prognosis}

\section{History}

Clinical interest in HFpEF emerged from the confluence of two research areas, one dealing with left ventricular diastolic dysfunction (LVDD) in hypertrophied hearts and the other with left ventricular (LV) remodeling post myocardial infarction (MI) [10]. In the late 1970s, studies began reporting association between LVDD and HF in patients with hypertrophic cardiomyopathy (HCM) [11,12], aortic stenosis [12,13] and hypertensive heart disease [14]. Consequently, HFpEF was recognized and investigated as a secondary outcome in large HF trials on the use of angiotensin converting enzymes (ACE)inhibitors in HFrEF in post-MI LV remodeling [15-17]. However, the HFpEF population recruited in these early large trials consisted of patients with limited MI at risk of eccentric LV remodeling. Several secondary analysis provided substantial natural history of HFpEF but also contributed to the present confusion surrounding the recognition of HFpEF as a distinct diagnosis [10]. Initially, HFpEF was termed diastolic HF because of the presence of LVDD evident from slow LV relaxation and increased LV stiffness, which distinguishes it from systolic HF traditionally associated with HFrEF. However, subsequent studies demonstrated that LVDD is not unique to HFpEF (also observed in HFrEF patients with a better correlation with symptoms) and the term abandoned and replaced by HFpEF or HF with normal EF (HFnEF) [18-20]. Despite acceptance, the term HFpEF is nondefinitive since the ideation of a preserved LVEF already implies knowledge of a pre-existing EF but which is often always absent and the precise range of preserved LVEF is difficult to define $[21,22]$. It is also not well established whether HFpEF and HFrEF represent distinct forms of HF or are part of one HF spectrum [23] irrespective of the two exhibiting two distinct patterns of cardiac chamber and myocellular remodeling as well as disparate responses to medical therapies suggesting two discrete disease processes [10].

${ }^{*}$ Correspondence to: Aref Albakri, St-Marien hospital Bonn Venusberg, Department of internal medicine, Bonn, Germany, E-mail: arefalbakri@yahoo.com

Key words: heart failure with preserved ejection fraction, heart failure with normal ejection fraction, diastolic heart failure

Received: October 08, 2018; Accepted: October 17, 2018; Published: October 25,2018 


\section{Definition}

Heart failure defines a complex clinical syndrome characterized by the inability of the heart to provide organ perfusion at a rate sufficient to meet the metabolic demands of the organs or doing so at the expense of elevated filling pressures [24]. The definition applies to both HFpEF and HFrEF phenotypes, and indeed, they exhibit comparable clinical signs, symptoms, functional limitations, morbidity and mortality [25]. Traditionally, HF has been measured based on pump dysfunction using LV ejection fraction by echocardiography. The traditional threshold for defining HFpEF has been echocardiography-defined EF ( $>50 \%)$ in the presence of overt $\mathrm{HF}$ while $\mathrm{HFrEF}$ is $\mathrm{EF}<40 \%$ [3,5,10,26-29]. Although the utility of EF alone in distinguishing HFpEF and HFrEF may be flawed [30,31], it is unlikely to be supplanted in the near future because of widespread availability of echocardiography and well-documented risk factors, pathophysiology and clinical outcomes in both phenotypes based on EF characterization [10,28]. Diastolic and systolic dichotomy have also been used to define and distinguish HFpEF from HFrEF but conceptual confusion exists [32]. Cardiovascular disease may cause diastolic dysfunction but isolated systolic dysfunction is very unlikely in clinical practice. A subset of patients with diastolic dysfunction may develop systolic dysfunction (Figure 1). Although diastolic dysfunction is one of the principal causes of HFpEF, it is not specific to HFpEF and systolic dysfunction may occur in some HFpEF patients but not consistently and depends on the index of systolic function used [33-35].

\section{Epidemiology}

The prevalence of HF varies based on the applied definition but estimated at 1 to $2 \%$ of the adult population in developed countries and increasing to $\geq 10 \%$ in people aged $>70$ years old [36-39]. The prevalence of HFpEF relative to HFrEF is increasing rapidly at the rate of approximately $1 \%$ annually, which may turn HFpEF the most prevalent HF phenotype over the next decade [10]. Data on temporal trends indicates the incidence of hospitalized HF is decreasing with the HFrEF phenotype reporting a more pronounced decrease $[40,41]$. The proportion of HFpEF patients in HF ranges widely between 22 and $73 \%$ based on the definition used, the clinical setting, age and sex of the studies population, previous $\mathrm{MU}$ and publication year $[38,42$ -

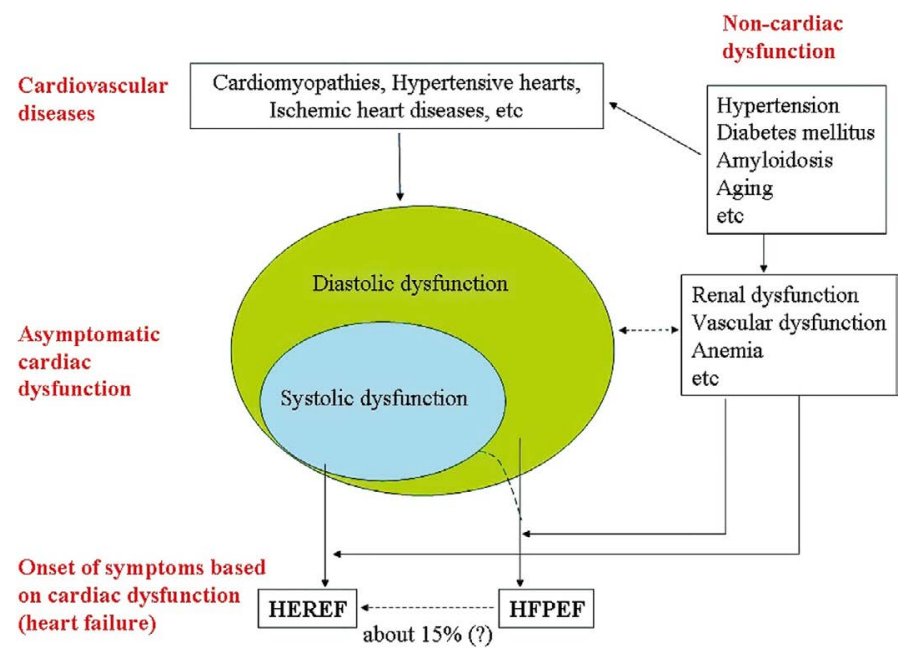

Figure 1. Transition from Cardiovascular Diseases to Heart Failure

Clinical distinction between HFpEF and HFrEF is lacking. Cardiovascular diseases cause diastolic dysfunction with or without systolic dysfunction. Systolic dysfunction without diastolic dysfunction is unlikely in clinical practice. Dysfunction of other organs may contribute to CVD and HF symptoms. About $15 \%$ of patients with HFpEF may develop HFrEF. Adapted from Yamamoto et al., 2009, pg. 405 [32]
46]. The prevalence of HFpEF is higher in women while HFrEF is higher in males. Overall HFpEF increases with age particularly among patients $>64$ years $[47,48]$. Patients with $\mathrm{HFpEF}$ are more likely to be female, have a higher body mass index $\left(B M I>30 \mathrm{~kg} / \mathrm{m}^{2}\right)$ with a lower hemoglobin compared to HFrEF. The prevalence of hypertension and atrial fibrillation $(\mathrm{AF})$ is higher but that of coronary artery disease and valve disease were lower compared to HFrEF [41].

\section{Prognosis}

Early observational studies (mostly retrospective) provide inconclusive and at most contradictory prognostication of HFpEF compared to HFrEF [49-51]. Data mostly drawn from ambulatory populations with insufficient information on hospitalized patients reveals HFpEF has a better prognosis based on survival relative to HFrEF $[50,52,53]$ but some studies also reveal comparable survival rates irrespective of pump dysfunction (EF values) [51,54-56]. Recent prospective studies suggest comparable short-term survival rates for HFpEF and HFrEF. A five-year population-based prospective study [57] reports similar survival rates for HFpEF vs. HFrEF at 1, 3, and 5 years are $78 \%$ vs. $74 \%, 58 \%$ vs. $57 \%$ and $43 \%$ vs. $46 \%$. The risk of cardiovascular and non-cardiovascular related deaths between HFpEF and HFpEF are also comparable (HR, 1.15; 95\% CI, 0.87-1.53; $\mathrm{p}=0.32$ ) and (HR, 1.06; 95\% CI, $0.69-1.61 ; \mathrm{p}=0.81)$. Significant independent predictors of poor prognosis in HFpEF are older age, AF on admission, history of MI, and co-morbidities (diabetes, stroke, peripheral artery disease) and cancer and anemia [57]. Another prospective populationbased study [58] reports mortality rates for HFpEF are lower compared to HFrEF at 30 days (5.3\% and $7.1 \%)$ and at one year (22.2\% and $25.2 \%)$ but the difference was not significant. One-year hospital re-admission rates for HFpEF (13.5\%) are also lower compared to HFrEF (16.1\%) but the difference is not significant. Significant predictor of death for HFpEF patients are older age, presence of systolic dysfunction, peripheral vascular disease, hyponatremia (serum sodium $<135 \mathrm{mEq} / \mathrm{l}$ )), a history of cancer, renal dysfunction and anemia [58].

\section{Etiopathophysiology}

The exact pathophysiological perturbation resulting into HFpEF remains incompletely defined. The traditional model places a strong emphasis on LV remodeling due to hypertension (afterload or increased pressure overload) as the principal pathophysiologic mechanisms for inflammation and primary stimulus for LV hypertrophy and diastolic dysfunction [9,59] (Figure 2A). On the other hand, the emerging model suggests pro-inflammatory cardiovascular and non-cardiovascular comorbidities leading to systemic microvascular endothelial inflammation global cardiac and skeletal muscle inflammation and subsequent fibrosis (Figure 2B).

\section{Traditional (hypertensive) model}

In Figure 2, the traditional model implicates hypertension as the cardinal pathophysiological mechanisms for the development of HFpEF. The isolation of hypertension was based on many early studies reporting that most patients with HFpEF have a history of hypertension. Systemic vascular dysfunction due to hypertension causes pressure overload, which leads to concentric LV hypertrophy and fibrotic remodeling and diastolic dysfunction. Ultimately, LVDD leads to atrial hypertension and remodeling, pulmonary venous hypertension and RB and atrial remodeling and dysfunction. Chronic left atrial hypertension and consequent structural and electric remodeling explains the high prevalence of atrial fibrillation in HFpEF patients. However, emerging evidence suggest insufficiency of the traditional model to explain the pathophysiology of HFpEF based on hypertension. 
Albakri A (2018) Heart failure with preserved ejection fraction: A review of clinical status and meta-analysis of diagnosis by myocardial strain and effect of medication on mortality and hospitalization

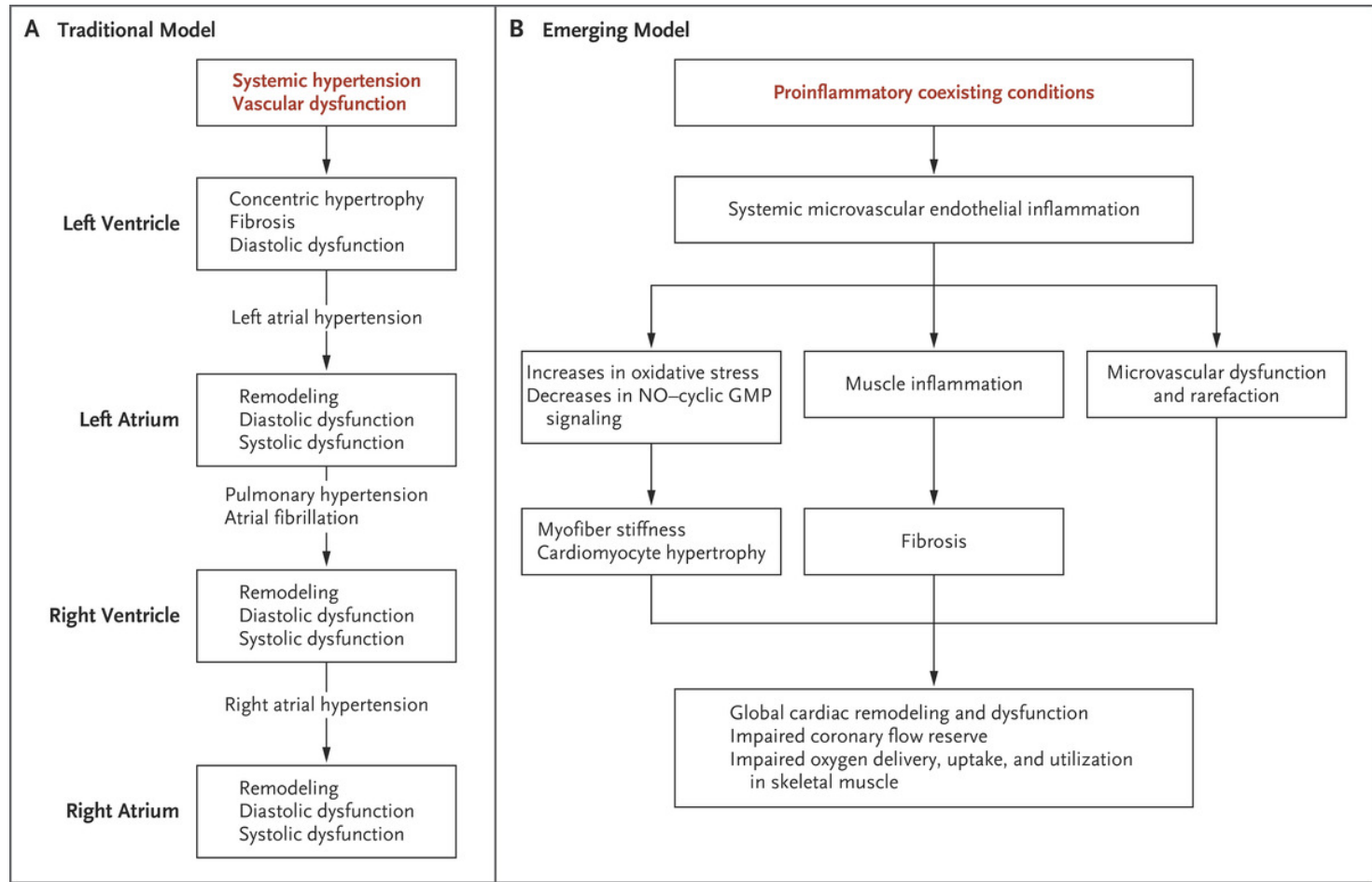

Figure 2. Traditional and Emerging Model of Pathophysiologic Mechanisms of HFpEF [59]

In the traditional model, pressure overload leads to concentric LV hypertrophic and fibrotic remodeling and diastolic dysfunction. LV diastolic dysfunction leads to left atrial (LA) hypertension and remodeling, pulmonary venous hypertension, and RV and atrial remodeling and dysfunction. Atrial fibrillation is common because of chronic LA hypertension. In the emerging model, pro-inflammatory cardiovascular and non-cardiovascular co-existing conditions lead to systemic microvascular endothelial inflammation, cardiac and skeletal muscle inflammation and fibrosis. These conditions lead to increased oxidative stress limiting nitric oxide production. Coronary microvascular inflammation results into microvascular dysfunction and rarefaction with reduced microvascular density and coronary flow reserve

On average, HFpEF patients have a higher LV mass (hypertrophy) compared to healthy controls or hypertensive patients without HF secondary to concentric remodeling $[60,61]$ but $40 \%$ of these patients fail to meet the echocardiography criteria for LV hypertrophy [62] or the severity of hypertrophy fails to distinguish between hypertensive patients with or without HF [63]. Over time, LV systolic and diastolic stiffness increases in older patients despite increased used of antihypertensive therapy and decreased LV mass, casting doubts on the central role of progressive hypertrophic remodeling causing LV dysfunction in HFpEF [64]. Additionally, resting diastolic dysfunction may be common in hypertensive patients and may be unrelated to the presence or severity of LV hypertrophy [65]. In both invasive [63,64] and non-invasive LV assessment $[28,66]$, HFpEF patients exhibit more impaired LV relaxation and diastolic stiffness compared to healthy or hypertensive controls without HF [67] but diastolic dysfunction and elevated filling pressures may be absent at rest in patients with impaired diastolic reserve [37].

Despite reports that diastolic dysfunction plays a cardinal role in the onset of HFpEF symptoms, non-invasive evidence of diastolic dysfunction is frequent in older patients without HFpEF. Thus, resting diastolic dysfunction plays a role but not sufficient in isolation to produce HFpEF [67]. The presence of increased LV diastolic stiffness implied by elevated resting LV filling pressures in HFpEF has also been demonstrated by invasive estimates of diastolic stiffness and by invasive pressure volume analysis [60]. However, the concept of heightened myocardial stiffness as a passive condition due to myocardial fibrosis has been abandoned based on the evidence that fibrosis and elevated collagen stiffness resulting from collagen cross-linking are present in HFpEF and linked to increased LV diastolic stiffness. Diastolic myocardial stiffness is also elevated in patients without evidence of increased fibrosis and acute changes in myocardial diastolic stiffness could occur secondary to ischemia [68].

In addition to LV hypertrophy and dysfunction, the exact contribution of left atrium to the pathophysiology of HFpEF in the traditional model also remains unclear. Usually, HFpEF patients have enlarged left atrium (LA) and the extent of atrial remodeling provides an approximate index of the severity or chronicity of HFpEF [69]. A reduction in LA compliance due to atrial volume overload or upward shift of the LA pressure-volume relationship contributes to mean LA pressures. PASP and right heart load in left heart disease and presents as large $\mathrm{V}$-waveforms during exercise and in the absence of mitral regurgitation. The waveforms are hemodynamic hallmark of HFpEF [67]. Chronic LA pressure overload and structural remodeling in $\mathrm{HFpEF}$ may result in electrical remodeling predisposing patients to $\mathrm{AF}$, which is present in about $66 \%$ of HFpEF patients at some point during the natural course of the disease [70]. However, it is unclear whether AF is a prognostic marker for advanced LVDD and HF or contributes to the progression of HFpEF through perturbed atrioventricular synchrony or heart rate, or impaired LA compliance $[9,67]$. Several other factors may contribute to the pathophysiology of HFpEF include enhanced aortic stiffness, and impaired ventricular vascular coupling [71], chronotropic incompetence [72,73], and decreased vasodilator reserve [73] and pulmonary hypertension $[63,74]$.

\section{Emerging (comorbidities) model}

The emerging model on the pathophysiology of HFpEF postulates endothelial dysfunction in the setting of pro-inflammatory cardiovascular and non-cardiovascular comorbidities plays a central 
role in the development of HFpEF [9]. The support for the emerging model is the prevalence of various co-morbidities in HFpEF patients such as hypertension, diabetes, obesity, chronic kidney disease (CKD) and anemia frequently associated with poor prognosis and treatment outcomes [75]. The emerging model proposes a sequent of five key pathophysiologic mechanisms of HFpEF [76] (Table 1).

Comorbidities and pro-inflammatory state: Cardiovascular and non-cardiovascular comorbidities are very prevalent in HFpEF patients [75]. The main comorbidities include obesity, hypertension, diabetes mellitus, chronic obstructive pulmonary disease (COPD), anemia and $\mathrm{CKD}$, which could induce a systemic inflammatory state [75,77]. In HFpEF, COPD causes chronic inflammation and is an independent predictor of mortality. Visceral obesity causes infiltration of macrophages into adipose tissue and produce pro-inflammatory cytokines leading to a systemic inflammatory state [78]. Obesity is also a significant prognostic marker for mortality based on a $U$ shaped association between body mass index (BMI) and HFpEF mortality [79]. In hypertensive salt-sensitive patients, high salt intake may cause systemic oxidative stress due to renal secretion of pro-inflammatory cytokines [80,81]. In HF patients in the presence or absence of anemia, iron deficiency contributes to immune responses and oxidative stress [82]. Although arterial hypertension a key pathophysiologic mechanism of HFpEF, comorbidities cause a more pronounced deterioration of myocardial function and structure in HFpEF patients $[76,83]$. Comorbidities-induced systemic inflammatory states is a predictor of HFpEF incident but not HFrEF [84]. Systemic inflammatory state in HFpEF patients is evidence in high circulating concentration of interleukin 6 (IL-6) and tumor necrosis factor $\alpha$ (TNF- $\alpha$ ) [76,85] and plasma levels of soluble ST2 and pentraxin $3[86,87]$.

Endothelial inflammation and nitric oxide bioavailability: In myocardial biopsy samples, systemic inflammation state due HFpEF comorbidities causes over-expression of endothelial adhesion molecules - vascular cell adhesion molecule and E-selectin leading to the activation and sub-endothelial migration of circulating leukocytes [88]. Pro-inflammatory cytokines may also cause ECs to secrete ROS leading to high nitrosative/oxidative stress. High nitrotyrosine expression suggests limited NO bioavailability in HFpEF myocardium due to the scavenging of $\mathrm{NO}$ by superoxide anion to form peroxynitrite. Some comorbidities such as diabetes mellitus and physiological processes such as aging may increase secretion of ROS by the ECs. Aging and the exposure of the ECs to high glucose concentration causes fragmentation and dysfunction of mitochondria, secretion of ROS and the formation of nitrotyrosine $[89,90]$. Coronary ECs inflammation causes a reduction in vasodilator response of the microvascular bed, which correlates with LVDD [91].

Table 1. Five key pathophysiologic mechanisms in HFpEF

\section{Steps Description of the Pathophysiologic Processes}

Cardiovascular and non-cardiovascular co-morbidities, especially obesity induce a pro-inflammatory state

Pro-inflammatory state causes coronary microvascular endothelial cells (ECs) to

2 produce reactive oxygen species (ROS) limiting bioavailability of nitric oxide (NO).

3 Limited NO bioavailability causes a reduction in protein kinase $\mathrm{G}(\mathrm{PKG})$ in cardiac myocytes

Low PKG activity inhibits cardiac myocytes hypertrophy to induce concentric LV

4 remodeling and stiffens cardiac myocytes die to hypophosphorylation of the giant cytoskeletal protein tintin

Stiffened cardiac myocytes and increased collagen deposition by myofibroblasts

5 lead to LV dysfunction, the hallmark of functional deficit in $\mathrm{HFpEF}$
Limited nitric oxide bioavailability and protein kinase g activity: Limited nitric oxide (NO) bioavailability and high peroxynitrite concentration inhibits the production of cyclic guanosine monophosphate (cGMP) by cardiac myocytes adjacent to dysfunctional ECs. Myocardial homogenates of HFpEF reveal low cGMP and decreased PKG activity [92,93]. Serum peptides such as B-type natriuretic peptide (BNP) particulate guanylate cyclase signaling is not able to preserve cGMP levels in HFpEF myocardium due to low diastolic wall stress in concentrically remodeled LV, which supports the low levels of BNP in HFpEF patients and the use of neprilysin inhibition to minimize the breakdown of BNP $[92,94]$. Low pkg activity and myocardial hypertrophy, relaxation and stiffness: PKG activity has been demonstrated in both clinical settings and experimental animal models to inhibit or even reverse myocardial hypertrophy [95,96]. In mice models, sildenafil (increases myocardial PKG activity) inhibited or reversed cardiac myocyte hypertrophy, while in diabetic patients caused a reduction in LV mass $[96,97]$. The relationship between myocardial PKG activity and cardiac myocyte hypertrophy is also evident in patients with aortic stenosis who exhibited less PKG activity but increased cardiac myocyte hypertrophy when diabetes mellitus was a comorbidity $[95,98]$. The endothelium to myocardium NO-cGMP-PKG signaling and high concentration of peroxynitrite also affect myocardial relaxation and explain the high resting tension at high pacing frequencies observed in isolated HFpEF myocardial strips [99]. The endothelium to myocardium NO-cGMP-PKG signaling also regulates myocardial stiffness. Infused NO decreased LV diastolic stiffness in human controls with aortic stenosis and dilated cardiomyopathy [100]. Sildenafil, which inhibits NO-mediated effects decreases diastolic stiffness in both animal models and humans [76]. Titin, a cytoskeletal protein, responsible for early cardiac myocytes diastolic recoil and late distension modulated through phosphorylation by PKG. cardiac myocytes from HFpEF patients have a high resting tension attributed to hypophosphorylation of titin [101].

Stiff cardiac myocytes, fibrosis and diastolic dysfunction: Stiffened cardiac myocytes described by increased collagen volume fraction, elevated expression of Collagen Type I and collagen cross-linking, contribute to LVDD [102]. The differentiation of fibroblast into myofibroblasts migrating from inflamed microvascular ECs could also lead to increased myocardial collagen deposition in HFpEF patients. ECs inflammation also augments proliferation of fibroblasts and myofibroblasts due to reduced nitric oxide bioavailability [76]. Arteria hypertension, very prevalent in HFpEF patients, has been linked with oxidative stress and microvascular inflammation lowering myocardial NO bioavailability to allow pre-hypertrophic stimuli induced by myocardial afterload (pressure overload) [76].

\section{Clinical presentation and diagnosis}

\section{Signs and symptoms}

Clinical signs and symptoms of HFpEF are non-specific and diagnosis requires a high index of suspicion with patients with significant risk factors or clinical signs and symptoms [59]. HFpEF should be suspected in patients presenting with typical signs of chronic heart failure: fatigue, weakness, dyspnea, orthopnea, peripheral edema and clinical signs such as third heart sound, jugular venous distension [103]. Specifically, HFpEF patients are more likely to be older, female, obese, lower hemoglobin compared to HFrEF and normal controls. Greater majority of HFpEF patients present with cardiovascular and non-cardiovascular comorbidities especially arterial hypertension. Other frequently encountered comorbidities are atrial fibrillation, 
Albakri A (2018) Heart failure with preserved ejection fraction: A review of clinical status and meta-analysis of diagnosis by myocardial strain and effect of medication on mortality and hospitalization

obesity, anemia diabetes and CKD [26]. A key clinical marker of HFpEF is exertional breathlessness and hemodynamic hallmark is an abnormal rise in pulmonary capillary wedge pressure and pulmonary artery pressure during exercise but at rest HFpEF have the same hemodynamic profiles with HFrEF and normal controls [104]. However, breathlessness is challenging to interpret in elderly and obese HFpEF patients, who form a large proportion of HFpEF patients [23].

\section{Diagnosis criteria and work-up}

The diagnosis of HFpEF is challenging because of the preserved LVEF and non-specific signs and symptoms that do not clearly discriminate HFpEF and other clinical conditions, and lack s validated gold standard diagnostic method. In particular, HFpEF diagnosis in the elderly with comorbidities and no signs of central fluid overload is difficult and cumbersome. To improve diagnostic specificity, several expert associations have published guidelines providing objective measures of cardiac dysfunction at rest and/or during exercise [23] (Table 2).

These early guidelines were published when HFpEF was assumed to be purely a diastolic dysfunction, affected about a third of HF patients, and its natural history was considered to be more benign compared to systolic heart failure [23]. Ove the past two decades, changes in epidemiology, additional knowledge on pathophysiology mechanisms and predisposing medical conditions, and the presence of LV diastolic dysfunction in other heart conditions, which made re-appraisal of diagnostic guidelines eminent [10]. However, these early guidelines provided the basis for the diagnosis of HFpEF, which included obligatory signs and/or symptoms of HF, evidence of normal systolic function, evidence of LVDD or surrogate markers of LVDD such as LV hypertrophy, LA enlargement, AF or elevated plasma natriuretic peptides [23].

The most recent guidelines are the 2016 ESC guidelines for the diagnosis and treatment of acute and chronic heart failure [108] and the 2013 American College of Cardiology Foundation/American Heart Association (ACCF/AHA) guidelines for the management of heart failure [29]. The two guidelines classify HF into two distinctive syndromes by measures of pump dysfunction: typically, echocardiography-defined LVEF ( $\leq 40 \%$ ). However, the two criteria have important differences. The ESC provides specific classification and diagnosis of HFpEF while the ACCF/AHA is more general, based on classification of HF into four stages (A to D) defined by the absence or presence of HF symptoms and structural heart disease (Table 3).

The 2016 ESC guidelines is more specific for HFpEF and detailed, based on clinical signs and symptoms and the presence of normal or mildly dilated LV or the presence of structural and/or functional heart disease. The 2016 ESC diagnosis requires the fulfillment of four criteria:

i) Clinical signs and symptoms;

ii) Preserved $\operatorname{LVEF} \geq 45 \%$;

iii) Elevated levels of NPs (BNP $>35$ pg/mL and/or NT-proBNP $>125$ $\mathrm{pg} / \mathrm{mL}$ );

iv) Objective evidence of other cardiac functional and/or structural cardiac abnormalities underlying HF.

- LVEDV index $<97 \mathrm{~mL} / \mathrm{m}^{2}$

- LVEDD index $<29 \mathrm{~mm}^{2}$

- $\quad$ LVM index $>115 \mathrm{~g} / \mathrm{m}^{2}(\mathrm{M}) 95 \mathrm{~g} / \mathrm{m} 2$ (F)
Table 2. Earlier published diagnostic guidelines for HFpEF

\begin{tabular}{|l|c|l|}
\hline Expert Group/Study & Year & Diagnostic Guidelines \\
\hline $\begin{array}{l}\text { The European Study Group on } \\
\text { Diastolic Heart Failure [105] }\end{array}$ & 1998 & Evidence of LV diastolic dysfunction \\
\hline $\begin{array}{l}\text { The National Heart, Lung, } \\
\text { and Blood Institute (NHLBI) } \\
\text { Framingham Heart Study [106] }\end{array}$ & 2000 & $\begin{array}{l}\text { Presence of signs } \pm \text { symptoms of HF, normal } \\
\text { LVEF ( } 50 \% \text { ), and invasive evidence of LV } \\
\text { diastolic dysfunction }\end{array}$ \\
\hline $\begin{array}{l}\text { Yturralde and Gaasch from the } \\
\text { Lahey Clinic [107] }\end{array}$ & 2005 & $\begin{array}{l}\text { A scoring system of major and minor criteria, } \\
\text { LV hypertrophy and LA enlargement as } \\
\text { surrogate markers of diastolic LV dysfunction }\end{array}$ \\
\hline $\begin{array}{l}\text { The Heart Failure and } \\
\text { Echocardiography Associations } \\
\text { of the European Society of } \\
\text { Cardiology (ESC) [23] }\end{array}$ & 2007 & $\begin{array}{l}\text { Presence of signs } \text { symptoms of congestive } \\
\text { heart failure; presence of normal or mildly } \\
\text { abnormal LV systolic function; and evidence of } \\
\text { diastolic LV dysfunction }\end{array}$ \\
\hline
\end{tabular}

Table 3. Differences between the ESC and ACCF/AHA diagnostic criteria for HFpEF

\begin{tabular}{|c|c|c|}
\hline & The 2016 ESC Criteria [108] & $\begin{array}{l}\text { The } 2013 \text { ACCF/AHA Criteria } \\
\text { [29] }\end{array}$ \\
\hline Classification & $\begin{array}{l}\text { HFrEF } \\
\text { Symptoms } \\
\text { Signs } \\
\text { Reduced LVEF }(<45 \%) \\
\text { HFpEF } \\
\text { Symptoms } \\
\text { Signs } \\
\text { Normal/mildly reduced LVEF, LV } \\
\text { not dilated, relevant structural or } \\
\text { functional heart disease }\end{array}$ & $\begin{array}{l}\text { Stage A } \\
\text { At risk for HF with not structural } \\
\text { heart disease or symptoms } \\
\text { Stage B } \\
\text { Structural heart disease with no } \\
\text { symptoms } \\
\text { Stage C } \\
\text { Structural heart disease with prior } \\
\text { or current symptoms } \\
\text { Stage D } \\
\text { Refractory HF }\end{array}$ \\
\hline Diagnosis & $\begin{array}{l}\text { Should fulfil four conditions } \\
\text { Presence of HF signs } \pm \text { symptoms } \\
\text { Preserved LVEF ( } \geq 45 \% \text { ) } \\
\text { Elevated levels of NPs } \\
\text { Evidence of structural heart disease } \\
\text { (LVH/LAE) or diastolic dysfunction }\end{array}$ & $\begin{array}{l}\text { Based on Stage C (Symptomatic) } \\
\text { Known structural heart disease } \\
\text { Typical signs and symptoms } \\
\text { Preserved LVEF } \\
\text { a. } \quad \text { LVEF } \geq 50 \% \text { - } \\
\text { (HFpEF) } \\
\text { b. LVEF } 41-50 \% \text { - } \\
\text { (Borderline } \mathrm{HFpEF} \text { ) }\end{array}$ \\
\hline
\end{tabular}

F: Female; HFpEF: Heart failure with preserved ejection fraction; LAV: Left Atrial Volume; LVEDD: Left Ventricular End Diastolic Diameter; LVEDV: Left Ventricular End Diastolic Volume; LVEF: Left Ventricular Ejection Fraction; LVM: Left Ventricular Mass Indexed; M: Male.

- $\mathrm{LAV}$ index $>34 \mathrm{~mL} / \mathrm{m}^{2}$

- $\mathrm{E} / \mathrm{e}^{\prime} \geq 13$

- E' average $<9 \mathrm{~cm} / \mathrm{s}$

In case of uncertainty, a stress test of invasive measures of elevated filling pressures may be considered to confirm diagnosis.

Diagnosis of HFpEF begins with screening for signs and symptoms, which are similar for HFpEF and HFrEF. Presence of ECG abnormalities such as AF, LV hypertrophy and repolarization abnormalities makes diagnosis likely. A normal ECG and/or plasma concentrations natriuretic peptides $(\mathrm{BNP}<35 \mathrm{pg} / \mathrm{mL}$ and/or NT-proBNP $<125 \mathrm{pg} /$ $\mathrm{mL}$ ) make diagnosis highly unlikely. The next step is advance work-up to detect structural alterations such as LA volume index or LA mass index, and key functional alterations such as E/e' and e average. Other echocardiography-defined surrogate markers for improving diagnosis include longitudinal strain or tricuspid regurgitation velocity (TRV). Echocardiography diastolic stress test may be considered using semisupine bicycle ergometer exercise protocol (E/e') and pulmonary artery pressures (TRV), stroke volume and cardiac output changes with exercise and at rest [108]. However, diagnosis of HFpEF in patients with AF remains difficult since they have elevated levels of plasma NPs, which may require stratification by sinus rhythm (higher in AF patients). 


\section{Meta-analysis of hfpef diagnosis by myocardial strain}

Current clinical guidelines for HFpEF diagnosis recommend the assessment of structural and/or functional myocardial abnormalities using LV diastolic volume, dimension, mass, left atrial volume (LAV) and E/e' ratio using conventional echocardiography along with tissue Doppler imaging (TDI) [108]. However, accumulating evidence strongly suggest global myocardial strain could be a valuable parameter to characterize alterations in systolic contractility in HFpEF patients. Observation studies report that a decrease in myocardial systolic strain causes a drop in ejection fraction but that is not often the case in hypertrophic LV diseases and HFpEF, where ejection fraction remains normal [109]. Global longitudinal strain (GLS) has also been shown to be a robust, well-validated and reproducible parameter for assessing LV longitudinal deformation. Global myocardial strain measured using 2D speckle tracking echocardiography (STE) could provide important prognostic and diagnostic information on HFpEF patients. Thus the aim of this meta-analysis is to combine patient data from individual clinical trials to determine whether global myocardial (longitudinal) strain is altered (deformed) in HFpEF patients compared to HFrEF and/or healthy controls.

Search strategy and inclusion criteria: Published studies investigating global longitudinal strain (GLS) in HFpEF patients using two-dimensional (2D)-STE were searched in PubMed, Medline, EMBASE and Cochrane online libraries. The key terms used for article search included heart failure with preserved ejection fraction or heart failure with normal ejection fraction echocardiography, and longitudinal strain. Additional studies were located through screening of citations in the selected studies as well as review articles. The inclusion criteria were, the studies (a) recruited HFpEF patients defined by LVEF $\geq 45 \%$; (b) reported data on outcomes of 2D-STE defined GLS; and (c) reported data on healthy controls (normal or asymptomatic patients but with CVD risk factors) and/or HFrEF patients for comparison. There was no restriction on publication time and language. Studies recruiting the same population, the one with more readily extractable data or the most recent study was selected. To minimize bias, two reviewers independently screened all qualifying studies using title, abstract and full-text as well as abstracted data from the included studies. Any disagreement was resolved through consensus. Abstracted data included first author, publication year, patient characteristic (population, mean age and gender representation [percentage of male patients]), and global longitudinal strain values for HFpEF, HFrEF and/ or healthy controls and their p-values (Table 4).
Study characteristics and outcomes: Online search and screening of citations retrieved 857 potential studies. Title and abstract screening excluded 721 studies. Finally, after strict application of the inclusion/ exclusion criteria, twelve (12) studies were included in this metaanalysis [110-121]. All the studies compared GLS values between HFpEF patients and controls (asymptomatic or healthy patients). Six studies [112,113,115,118-120] compared GLS values between three groups of patients - HFpEF, HFrEF (or those systolic dysfunction) and controls. The twelve studies had a combined patient population of 2,405 constituting of 1,131 HFpEF patients, 533 systolic dysfunction patients, and 741 healthy controls. The mean age of the HFpEF patients was 68.25 years $(\mathrm{SD}=6.07$; range $57-78)$ with almost an equal gender representation (male HFpEF patients = 47\%; range 23-70). Left ventricular systolic function differed between HFpEF patients and controls. HFpEF patients had significantly lower GLS (mean $=-15.41 \%$; range $=-12 \%$ to $-18.9 \%$ ) than healthy controls (mean $=-19.14 \%$; range $=-15.90 \%$ to $-21.5 \%)$. In six studies $[112,113,115,118-120]$ that compared GLS in HFpEF and HFrEF patients, HFpEF had significantly higher GLS (mean $=-14.57 \%$; range $-12 \%$ to $-17 \%$ ) than HFrEF (mean $=-7.38 \%$; range $-4.0 \%$ to $-9.6 \%$ ).

Discussion: Heart failure with preserved ejection fraction (HFpEF) has traditionally been considered a cardiac syndrome characterized by principally by LV diastolic abnormalities. The involvement of LV diastolic alterations in HFpEF have been confirmed by their inclusion in the current ESC and AFFC/AHA clinical guidelines for HFpEF diagnosis $[29,108]$. Measurements of LV end-diastole volume, LV end diastolic dimensions, LV mass, LA volume, LA enlargement and LV hypertrophy have been the common recommended parameters in the diagnosis work up of HFpEF using echocardiography [109]. Recent evidence based on 2D-STE imaging modality demonstrates impairment of the LV longitudinal systolic function in HFPEF patients. However, with mixed findings on whether GLS in HFpEF patients is lower relative to healthy or asymptomatic patients, the present meta-analysis analysis sought to assemble evidence that GLS is an accurate parameter for assessing and detecting alterations in longitudinal systolic function (contractility) in HFpEF patients. The findings confirm that in HFpEF patients, GLS assessed by 2D-STE is significantly lower in comparison to healthy or asymptomatic patients but significantly higher than in HFrEF patients.

The finding that longitudinal systolic function of the LV is altered (significantly lower GLS) in HFpEF patients is consistent with several previous studies. Although earlier observation studies suggested a

Table 4. Summary of included studies in HFpEF diagnosis

\begin{tabular}{|c|c|c|c|c|c|c|c|c|c|c|}
\hline \multirow[t]{2}{*}{ 1st Author } & \multirow[t]{2}{*}{ Year } & \multicolumn{3}{|c|}{ Patient Sample Size } & \multirow{2}{*}{$\begin{array}{c}\text { HFpEF } \\
\text { Mean Age } \\
\text { (SD) }\end{array}$} & \multirow{2}{*}{$\begin{array}{c}\text { HFpEF } \\
\text { Male (\%) }\end{array}$} & \multicolumn{3}{|c|}{ Global Longitudinal Strain (\%) } & \multirow[t]{2}{*}{ p-value } \\
\hline & & HFpEF & Systolic & Controls & & & HFpEF & Systolic & Controls & \\
\hline Wang et al. [110] & 2008 & 50 & 30 & 17 & $58(16)$ & 65 & -12 & -4 & $-19(2.0)$ & $<0.001$ \\
\hline Liu et al. [111] & 2009 & 26 & 23 & 40 & $68(13)$ & 69 & -14 & -8 & -20 & $<0.001$ \\
\hline Phan et al. [112] & 2009 & 40 & NA & 26 & $67(10)$ & 27 & $-17.8(3.3)$ & NA & $-18.2(2.9)$ & $<0.763$ \\
\hline Tan et al. [113] & 2009 & 56 & NA & 67 & $72(7)$ & 30 & $-18.9(3.5)$ & NA & $-20.9(3.0)$ & 0.018 \\
\hline Yip et al. [114] & 2011 & 113 & 176 & 60 & $74(12)$ & 36 & $-15.9(3.9)$ & $-9.6(3.6)$ & $-20.9(2.5)$ & $<0.001$ \\
\hline Kraigher-Krainer et al [115] & 2014 & 219 & NA & 50 & $72(9)$ & 39 & $-14.6(3.3)$ & NA & $-20.0(2.1)$ & $<0.0001$ \\
\hline Luo et al. [116] & 2014 & 58 & 45 & 46 & $70(10)$ & 60 & $-14.02(2.7)$ & $-8.28(2.7)$ & $-17.1(2.1)$ & $<0.001$ \\
\hline Menet et al. [117] & 2014 & 40 & 40 & 40 & $70(13)$ & 23 & $-17(3.0)$ & $-7(3)$ & $-19(3.0)$ & $<0.001$ \\
\hline Pellicori et al. [118] & 2014 & 138 & NA & 76 & $78(10)$ & 63 & $-13.6(3.0)$ & NA & $-15.9(2.4)$ & $<0.001$ \\
\hline Toufan et al. [119] & 2015 & 126 & NA & 60 & $57(10)$ & 70 & $-17.3(3.5)$ & NA & $-20.6(1.8)$ & $<0.001$ \\
\hline Carluccio et al. [120] & 2016 & 46 & NA & 40 & $65(15)$ & 36 & $-15.4(3.5)$ & NA & $-21.5(2.9)$ & $<0.0001$ \\
\hline Bosch et al. [121] & 2017 & 219 & 219 & 219 & $68(11)$ & 48 & $-14.5(4.0)$ & $-7.4(7.3)$ & $-16.6(2.6)$ & $<0.05$ \\
\hline
\end{tabular}

NA: Not Applicable (did not include systolic/HFrEF patients) 
Albakri A (2018) Heart failure with preserved ejection fraction: A review of clinical status and meta-analysis of diagnosis by myocardial strain and effect of medication on mortality and hospitalization

link between ejection fraction and myocardial strain, it has been demonstrated that alterations in myocardial strain occur with a normal ejection fraction particularly in patients with hypertrophic LV disorders including HFpEF patients [109]. An Asian study reported impaired global longitudinal strain (GLS) defined by 2D-STE as < $15.8 \%$ ) is a significant predictor of HF-related hospitalization, CVDrelated mortality and aborted cardiac arrest in HFpEF patients [122]. In the present meta-analysis, mean GLS in HFpEF patients were $<15.8 \%$ suggesting significant alterations in LV longitudinal systolic function. Global longitudinal stress has also been shown to provide accurate assessment of LV systolic (contractility) function in patients with LV hypertrophy diseases and therefore a potential parameter for assessing LV longitudinal systolic dysfunction in HFpEF patients [109,119].

The present findings contribute new insights into HFpEF pathophysiology, and to improvement in diagnosis and treatment of HFpEF. Although current proposed pathophysiological mechanisms postulate that pro-inflammatory cardiac and extra cardiac comorbidities, endothelial inflammation cause a cascade of pathogenic processes ultimately leading to cardiac myocyte hypertrophy and collagen deposition [75-77], present findings suggest alterations in LV longitudinal strain is present in HFpEF patients. The present findings also suggest GLS as a potential echocardiography marker for assessment of global myocardial strain and complement the current parameters assessing LV mass, dimension and volume [108]. Finally, the present findings could provide important insight into treatment of HFpEF. Many clinical trials have investigated medical and non-medical to restore LV diastolic function in HFpEF patients with the goal of improving prognosis. However, none of the current treatment regimens including HF medication has been shown to decrease mortality in HFpEF patients [123]. For this reason, other pathophysiological mechanisms such as altered LV longitudinal systolic function may be considered to design new clinical trials and treatment for HFpEF, which currently lacks a specific treatment approach. Altered LV longitudinal systolic function has also been associated with a greater CVD-related mortality and hospitalization suggesting its prognostic relevance warranting large clinical trials for validation.

\section{Clinical management}

\section{Guidelines for clinical management}

Both the ESC [108] and the ACCF/AHA [29] have published guidelines for clinical management of HFpEF but no treatment has demonstrated a reduction in morbidity or mortality (Table 5).

\section{Treatment approaches}

Treatment for HFpEF phenotype is challenging due to the lack of a precise definition. Whereas the HFrEF phenotype requires LVEF < $40 \%$, that of $\mathrm{HFpEF}$ is less specific. Defined as LVEF $\geq 50 \%$, patients with LVEF 40 to $49 \%$ (heart failure with mildly reduced LVEF $[\mathrm{HFmEF}]$ ) are often included in treatment guidelines and protocols for HFpEF. With availability of additional new data and analysis, it may be possible to have different treatment recommendations for the HFpEF and HFmEF phenotypes, which is currently lacking. Although the use of medical therapy such as diuretics, beta-blockers, angiotensinconverting enzyme (ACE)-inhibitors/angiotensin II Type I receptor blockers (ARB), and mineralocorticoid receptor antagonist (MRA) are effective in HFrEF, fewer HFpEF patients receive these medications [94,123-125].

The limited use of traditional HF medication may suggest focus on the treatment of comorbidities such as hypertension, atrial
Table 5. Summary of the ESC and the ACCF/AHA HFpEF management guidelines

\begin{tabular}{|l|l|l|}
\hline $\begin{array}{c}\text { The 2016 ESC Guidelines for the } \\
\text { diagnosis and treatment of acute and } \\
\text { chronic heart failure }\end{array}$ & $\begin{array}{c}\text { The 2013 ACCF/AHA Guidelines for the } \\
\text { management of heart failure }\end{array}$ \\
\hline Class I & $\begin{array}{c}\text { Control of blood pressure (LoE B) } \\
\text { Diuretics to relieve symptoms (LoE C) }\end{array}$ \\
\hline Class IIa & $\begin{array}{c}\text { No treatment has shown to } \\
\text { reduce morbidity and mortality } \\
\text { in HFpEF }\end{array}$ & $\begin{array}{l}\text { Coronary revascularization in CAD } \\
\text { (symptomatic or MI) (LoE C) }\end{array}$ \\
\hline \begin{tabular}{l} 
Class IIb \\
\hline
\end{tabular} & $\begin{array}{l}\text { Af management (LoE C) } \\
\beta \text {-blockers (LoE C) }\end{array}$ \\
\hline
\end{tabular}

LoE: Level of Evidence; Class I, IIa, IIb: Class of recommendations

fibrillation or coronary artery disease or a reduction in the new onset of the HFpEF phenotype in current clinical trials or the failure to distinguish between guidelines for HFpEF and HFrEF phenotypes $[108,126]$. Reduced use of HF medication support reports that the pathophysiology of HFpEF is heterogeneous and frequently associated with various cardiovascular comorbidities (arterial hypertension, $\mathrm{AF}, \mathrm{CAD}$ and pulmonary hypertension) and non-cardiovascular comorbidities (CKD, COPD, anemia and obesity) [75,76].

Relative to HFrEF, a greater proportion of HFpEF deaths are associated with non-cardiovascular comorbidities [76,108]. Due to the high prevalence of comorbidities in HFpEF patients, The 2016 ESC guidelines recommend screening for cardiovascular and noncardiovascular comorbidities, and if present, the primary therapeutic target should be their management using validated interventions to improve symptoms, well-being and clinical outcomes [108]. Currently, no treatment has shown convincing outcomes in reducing morbidity/ mortality in HFpEF patients. However, most of HFpEF patients are elderly and highly asymptomatic with poor quality of life [127]. Thus, important therapeutic target in HFpEF patients are to alleviate symptoms and to improve well-being [108] (Table 6).

\section{Meta-analysis of hfpef medical therapy on mortality/ hospitalization}

Patients with HFpEF constitute about $50 \%$ of patients with HF and their prevalence is increasing [10]. Unlike HFrEF, which has welldemonstrated treatment benefits, HFpEF patients lack specific treatment guidelines, and therapy usually focuses on treating comorbidities. Whether the conventional medical therapy for HF convey clinical benefits to HFpEF patients remains unclear. Large-scale clinical trials investigating conventional HF medical therapy have reported mixed outcomes on whether HFpEF patients have similar survival or HF-hospitalization rates compared to HFrEF patients. The aim of the present meta-analysis is to determine whether medical therapy improves survival rates and/or reduces CVD-related hospitalization for HFpEF patients compared to placebo group.

Search strategy and inclusion criteria: A systematic search for studies investigating clinical outcomes of medical therapy on HFpEF patients was done on online databases PubMed, Medline, EMBASE and Cochrane. The search used a combination of key words including heart failure, diastolic heart failure, heat failure preserved ejection fraction, or heart failure normal ejection fraction. Based on the results of the search, interventional and observational studies investigating medications on HFpEF patients were identified. To ensure as many as possible studies were identified, the citations of each potential study was 
Albakri A (2018) Heart failure with preserved ejection fraction: A review of clinical status and meta-analysis of diagnosis by myocardial strain and effect of medication on mortality and hospitalization

scrutinized for additional study not identified by the online search. The inclusion criteria included studies that (a) recruited patients diagnosed with HFpEF (documented LVEF $\geq 35 \%$ ); (b) provided information comparing drug therapy with controls (placebo, no treatment, diuretic treatment or standard medical treatment); (c) provided information on primary and secondary endpoints (mortality and/or hospitalization); and (d) followed patients for at least 12 months. The exclusion criteria included trials (a) where EF could not be determined or substantiated; (b) pertinent data to analysis was not available; and (c) conference papers, which are subject to changes (are not final). However, studies were not excluded based on publication year and language. Two experienced reviewers screened the studies against the inclusion criteria and resolved any disagreement by consensus. Clinical, echocardiographic and outcome data were abstracted from all the included studies and entered into Microsoft Excel file. The collated data included author and publication year, patient population, cut-off LVEF, primary medication administered, hospitalization and mortality rates, and follow-up period (Table 7).

Study characteristics and outcomes: The electronic search and scrutiny of citations yielded 3161 articles. These articles were screened and evaluated for eligibility based on abstract and title only to remove duplicates and non-relevant studies. A further full-text evaluation was the conducted on all the remaining potential articles against the inclusion/exclusion criteria. Ultimately, eleven (11) studies were included in this meta-analysis $[6,8,128-136]$. The combined patient population in the eleven studies was 13,321 consisting of $6,650 \mathrm{HFpEF}$ patients in study group (receiving medication) and 6,670 in the control group. The wide range of HF medications studied included candesartan, nebivolol, digoxin, perindopril, irbesartan, diuretic and beta-blockers (metoprolol, carvedilol and bisoprolol). The cut-off LVEF values for recruiting of HFpEF patients varied among studies (mean $\mathrm{LVEF}=40 \%$; range $35 \%$ to $45 \%$ ). Within a mean follow-up period of
24.4 \pm 10.7 months, there was no significant differences in CVD-relatedhospitalization rates for HFpEF patients on HF medication (15.7\%) and control group (14\%), and in mortality rates (18.3\%) and $(21.3 \%)$ respectively.

\section{Discussion}

Whereas HFrEF has evidence-based therapies, $\mathrm{HFpEF}$ lacks proven treatment. The current ESC and ACCF/AHA guidelines recommendation treatment of the precipitating co-morbidities [108]. However, the clinical benefits of these therapies on hard end-points (mortality and hospitalization) are often anticipated instead of proven in HFpEF patients. Although the traditional HF medication is usually administered to HFpEF patients, mixed outcomes from large-scale trials has made their clinical benefits unclear. This meta-analysis sought to aggregate evidence from individual large-scale studies to assess the effect of various HF medication on hospitalization and/or mortality in HF patients. This meta-analysis finds HF medication does not cause significant reduction in both mortality and hospitalization rates in HFpEF patients relative to controls.

The present findings are consistent with those of three related meta-analysis on the effect of medication on survival, quality of life and exercise tolerance [137-139]. Medical therapy in HFpEF patients demonstrates quantifiable improvement in exercise tolerance but does not cause any reduction in al-cause and CVD-related mortality [137]. HFpEF patients have a lower risk of death compared to HFrEF despite age, gender and HF etiology, but all-cause mortality is higher in HFpEF that HFrEF [139]. Comparing the effect of HF medication on survival in HFpEF patients, beta-blocker seems to have a superior protective effect on CVD-related mortality compared to other drug classes [138].

While medications might reduce mortality rates, the effect on HFpEF patients might be challenging to ascertain. HFpEF patients tend to be usually older, limited by disabling symptoms, poor quality

Table 6. Effect of medical therapy on HFpEF

\begin{tabular}{|l|l|l|}
\hline Effect of on... & Primary Medication & Symptom Improvement \\
\hline Symptoms & Diuretics & $\begin{array}{l}\text { Improve congestion is present and consequently improved signs and symptoms } \\
\text { of HF. }\end{array}$ \\
\hline & Beta-blockers/MRAs & NO evidence on symptom relief \\
\hline & ARBs/ACE-inhibitor & Inconsistent evidence. Only candesartan shows improvement in NYHA Class \\
\hline Hospitalization & Nebivolol, digoxin, spironolactone and candesartan & May reduce HF hospitalization for patients with sinus rhythm. \\
\hline & Beta-blockers & Not effective in reducing hospitalization in AF patients. \\
\hline & ACE-inhibitors/ARBs & Inconclusive evidence \\
\hline Mortality & Ace-inhibitors/ARBs, MRAs and beta-blockers & Failed to reduce mortality rates \\
\hline & Nebivolol & $\begin{array}{l}\text { In older patients reduced combines endpoint of death and cardiovascular } \\
\text { hospitalization. }\end{array}$ \\
\hline
\end{tabular}

Table 7. Summary of included studies on efficacy of HFpEF medical treatment

\begin{tabular}{|c|c|c|c|c|c|c|c|c|c|c|}
\hline \multirow{2}{*}{$\begin{array}{l}\text { 1st Author } \\
\text { [Ref \#] }\end{array}$} & \multirow[t]{2}{*}{ Year } & \multicolumn{2}{|c|}{ Patient Population } & \multirow{2}{*}{$\begin{array}{l}\text { LVEF } \\
(>\%)\end{array}$} & \multirow[t]{2}{*}{ Medication } & \multicolumn{2}{|c|}{ Hospitalization } & \multicolumn{2}{|c|}{ Mortality } & \multirow{2}{*}{$\begin{array}{c}\text { Mean Follow-up } \\
\text { (months) }\end{array}$} \\
\hline & & Study & Placebo & & & Study & Placebo & Study & Placebo & \\
\hline Yusuf et al. [8] & 2003 & 1514 & 1509 & 40 & Candesartan & 170 & 170 & 241 & 276 & 36.6 \\
\hline Flather et al. [128] & 2005 & 1067 & 1061 & 35 & Nebivolol & 123 & 145 & 256 & 276 & 21.0 \\
\hline Ahmed et al. [129] & 2006 & 492 & 496 & 45 & Digoxin & 115 & 116 & 89 & 108 & 37.0 \\
\hline Cleland et al. [130] & 2006 & 424 & 426 & 40 & Perindopril & 38 & 40 & 59 & 71 & 26.2 \\
\hline Dobre et al. [131] & 2007 & 227 & 216 & 40 & $\beta$-blockers & NR & NR & 40 & 73 & 25.0 \\
\hline Masie et al. [6] & 2008 & 2067 & 2061 & 45 & Irbesartan & 325 & 336 & 428 & 438 & 49.5 \\
\hline Yip et al. [132] & 2008 & 73 & 75 & 45 & Diuretic & 6 & 6 & 3 & 1 & 12.0 \\
\hline Van Veldhuisen et al. [132] & 2009 & 380 & 372 & 35 & Nebivolol & 85 & 94 & 33 & 39 & 21.0 \\
\hline Mulder et al. [134] & 2012 & 133 & 138 & 35 & Nebivolol & 44 & NR & 49 & 52 & 21.0 \\
\hline Nevzorov et al. [135] & 2012 & 154 & 191 & 40 & $\beta$-blockers & 120 & NR & NR & 77 & 24 \\
\hline Yamamoto et al. [136] & 2013 & 120 & 125 & 40 & Carvedilol & 21 & 27 & 8 & 7 & 38.4 \\
\hline
\end{tabular}


Albakri A (2018) Heart failure with preserved ejection fraction: A review of clinical status and meta-analysis of diagnosis by myocardial strain and effect of medication on mortality and hospitalization

of life and with a high prevalence of comorbidities. HFpEF patients also have a higher non-cardiovascular-related mortality [56,57]. There are suggestions for a shift towards exercise tolerance, quality of life and improvement in symptoms as better indicators of treatment efficacy in HFpEF patients compared to the traditional mortality and hospitalization rates [138]. Further, the lack of a universally acceptable LVEF cut-off for consideration for HFpEF medication may undermine the accuracy of analysis of treatment efficacy. Trials stratified by LVEF thresholds do not find any significant differences in clinical outcomes because of ending up with smaller heterogamous subgroups with inconclusive evidence [138]. The present findings suggest the need to evaluate treatment effect on specific HFpEF phenotypes (based on precipitating comorbidity) to identify subgroups that may benefit from treatment. Newer insights into the pathophysiology of HFpEF may also help to guide research and development of newer therapies.

\section{Conclusion}

Heart failure (HF) with preserved ejection fraction (HFpEF) is a clinical syndrome characterized by left ventricular diastolic dysfunction (LVDD) and /or systolic dysfunction and distinguished by pump dysfunction (left ventricular [LV] ejection fraction (EF) (LVEF > 50\%). It has the highest increasing prevalence in HF phenotypes, which is greater in women, the elderly, obese and diabetic patients. Significant markers for death or poor prognosis are older age, presence of systolic dysfunction, perivascular disease, hyponatremia, history of cancer, renal dysfunction, and anemia. Comorbidities are prevalence in HFpEF patients and implicated as the key causes of HFpEF pathophysiology. They induce systemic pro-inflammatory state leading to a sequence of events: microvascular endothelial inflammation, reduced nitric oxide (NO) and protein kinase G (PKG) activity, myocardial hypertrophy development, increased resting tension, and stiffened cardiac myocytes and interstitial fibrosis, elevated LV diastolic stiffness and ultimately the development of heart failure. The most frequent sign and symptom are exertional breathlessness and abnormal rise in pulmonary capillary wedge pressure and pulmonary artery pressure during exercise. Clinical diagnosis requires the presence of signs and symptoms of HF (fatigue, dyspnea, orthopnea, peripheral edema, third heart sound or jugular venous distension), preserved LVEF, elevated BNP and/or NT-proBNP, and evidence of structural heart disease or diastolic dysfunction. There are no specific therapies for HFpEF. There is limited use of the traditional HF medication to improve symptoms and reduce hospitalization but no significant effect on reducing mortality. However, the recommended treatment is the detecting and treatment of comorbidities.

\section{References}

1. Ponikowski P, Anker SD, AlHabib KF, Cowie MR, Force TL, et al. (2014) Heart failure: preventing disease and death worldwide. ESC Heart Fail 1: 4-25. [Crossref]

2. AmbrosyAP, Fonarow GC, Butler J, Chioncel O, Greene SJ, et al. (2014) The global health and economic burden of hospitalizations for heart failure: lessons learned from hospitalized heart failure registries. J Am Coll Cardiol 63: 1123-1133. [Crossref]

3. Yancy CW, Lopatin M, Stevenson LW, De Marco T, Fonarow GC, et al. (2006) Clinical presentation, management, and in-hospital outcomes of patients admitted with acute decompensated heart failure with preserved systolic function: a report from the Acute Decompensated Heart Failure National Registry (ADHERE) Database. $J$ Am Coll Cardiol 47: 76-84. [Crossref]

4. Shah SJ, Gheorghiade M (2008) Heart failure with preserved ejection fraction: treat now by treating comorbidities. Jama 300: 431-433. [Crossref]

5. Fonarow GC, Stough WG, Abraham WT, Albert NM, Gheorghiade M, et al. (2007) Characteristics, treatments, and outcomes of patients with preserved systolic function hospitalized for heart failure: a report from the OPTIMIZE-HF Registry. $J$ Am Coll Cardiol 50: 768-777. [Crossref]
6. Massie BM, Carson PE, McMurray JJ, Komajda M, McKelvie R, et al. (2008) Irbesartan in patients with heart failure and preserved ejection fraction. $N$ Engl J Med 359: 2456-2467. [Crossref]

7. Cleland JG, Tendera M, Adamus J, Freemantle N, Polonski L, et al. (2006). The perindopril in elderly people with chronic heart failure (PEP-CHF) study. Eur Heart J 27: 2338-2345. [Crossref]

8. Yusuf S, Pfeffer MA, Swedberg K, Granger CB, Held P, et al. (2003) Effects of candesartan in patients with chronic heart failure and preserved left-ventricular ejection fraction: the CHARM-Preserved Trial. The Lancet 362: 777-781. [Crossref]

9. Desai AS (2013) Heart failure with preserved ejection fraction: time for a new approach? J Am Coll Cardiol 62: 272-274. [Crossref]

10. Borlaug BA, Paulus WJ (2010) Heart failure with preserved ejection fraction pathophysiology, diagnosis, and treatment. Eur Heart J 32: 670-679. [Crossref]

11. Sanderson JE, Gibson DG, Brown DJ, Goodwin JF (1977) Left ventricular filling in hypertrophic cardiomyopathy. An angiographic study. Heart 39: 661-670. [Crossref]

12. Hanrath P, Mathey DG, Siegert R, Bleifeld W (1980) Left ventricular relaxation and filling pattern in different forms of left ventricular hypertrophy: an echocardiographic study. Am J Cardiol 45: 15-23. [Crossref]

13. Hess OM, Grimm J, Krayenbuehl HP (1979) Diastolic simple elastic and viscoelastic properties of the left ventricle in man. Circ 59: 1178-1187. [Crossref]

14. Soufer R, Wohlgelernter D, Vita NA, Amuchestegui M, Sostman HD, et al. (1985) Intact systolic left ventricular function in clinical congestive heart failure. . Am J Cardiol 55: 1032-1036. [Crossref]

15. Aronow WS, Kronzon I (1993) Effect of enalapril on congestive heart failure treated with diuretics in elderly patients with prior myocardial infarction and normal left ventricular ejection fraction. Am J Cardiol 71: 602-604. [Crossref]

16. Carson P, Johnson G, Fletcher R, Cohn J, V-HeFT Cooperative Study Group (1996) Mild systolic dysfunction in heart failure (left ventricular ejection fraction $>35 \%$ ): baseline characteristics, prognosis and response to therapy in the Vasodilator in Heart Failure Trials (V-HeFT). J Am Coll Cardiol 27: 642-649. [Crossref]

17. Aronow WS, Ahn C, Kronzon I (1997) Effect of propranolol versus no propranolo on total mortality plus nonfatal myocardial infarction in older patients with prio myocardial infarction, congestive heart failure, and left ventricular ejection fraction> or $=40 \%$ treated with diuretics plus angiotensin-converting enzyme inhibitors. $\mathrm{Am} \mathrm{J}$ Cardiol 80: 207-209. [Crossref]

18. McMurray J, Pfeffer MA (2002) New therapeutic options in congestive heart failure: Part II. Circ 105: 2223-2228. [Crossref]

19. Skaluba SJ, Litwin SE (2004) Mechanisms of exercise intolerance: insights from tissue Doppler imaging. Circ 109: 972-977. [Crossref]

20. Hadano Y, Murata K, Yamamoto T, Kunichika H, Matsumoto T, et al. (2006) Usefulness of mitral annular velocity in predicting exercise tolerance in patients with impaired left ventricular systolic function. Am J Cardiol 97: 1025-1028. [Crossref]

21. Davies MK, Hobbs FD, Davis RC, Kenkre JE, Roalfe AK, et al. (2001) Prevalence of left-ventricular systolic dysfunction and heart failure in the Echocardiographic Heart of England Screening study: a population based study. The Lancet 358: 439-444. [Crossref]

22. Petrie M, McMurray J (2001) Changes in notions about heart failure. The Lancet 358 432-434. [Crossref]

23. Paulus WJ, Tschöpe C, Sanderson JE, Rusconi C, Flachskampf FA, et al. (2007) How to diagnose diastolic heart failure: a consensus statement on the diagnosis of heart failure with normal left ventricular ejection fraction by the Heart Failure and Echocardiography Associations of the European Society of Cardiology. Eur Heart $J$ 28: 2539-2550. [Crossref]

24. Abudiab MM, Redfield MM, Melenovsky V, Olson TP, Kass DA, et al. (2013) Cardiac output response to exercise in relation to metabolic demand in heart failure with preserved ejection fraction. Eur J Heart Fail 15: 776-785. [Crossref]

25. Reddy YN, Borlaug BA (2016) Heart failure with preserved ejection fraction. Curr Probl Cardiol 41: 145-188. [Crossref]

26. Owan TE, Hodge DO, Herges RM, Jacobsen SJ, Roger VL, et al. (2006) Trends in prevalence and outcome of heart failure with preserved ejection fraction. $N$ Engl J Med 20;355: 251-259. [Crossref]

27. Bursi F, Weston SA, Redfield MM, Jacobsen SJ, Pakhomov S, et al. (2006) Systolic and diastolic heart failure in the community. Jama 296: 2209-2216. [Crossref] 
Albakri A (2018) Heart failure with preserved ejection fraction: A review of clinical status and meta-analysis of diagnosis by myocardial strain and effect of medication on mortality and hospitalization

28. Borlaug BA, Redfield MM (2011) Diastolic and systolic heart failure are distinct phenotypes within the heart failure spectrum response to Borlaug and Redfield. Circ 123: 2006-2014. [Crossref]

29. Yancy CW, Jessup M, Bozkurt B, Butler J, Casey DE, et al. (2013) 2013 ACCF/AHA guideline for the management of heart failure: a report of the American College of Cardiology Foundation/American Heart Association Task Force on Practice Guidelines. J Am Coll Cardiol 62: e147-239. [Crossref]

30. De Keulenaer GW, Brutsaert DL (2009). The heart failure spectrum: time for a phenotype-oriented approach. Circ 119: 3044-3046. [Crossref]

31. De Keulenaer GW, Brutsaert DL (2011) Systolic and Diastolic Heart Failure Are Overlapping Phenotypes Within the Heart Failure SpectrumResponse to De Keulenaer and Brutsaert. Circ 123: 1996-2005. [Crossref]

32. Yamamoto K, Sakata Y, Ohtani T, Takeda Y, Mano T (2009) Heart failure with preserved ejection fraction. Circ J 73: 404-410. [Crossref]

33. Yu CM, Lin H, Yang H, Kong SL, Zhang Q, et al. (2002) Progression of systolic abnormalities in patients with "isolated" diastolic heart failure and diastolic dysfunction. Circ 105:1 195-1201. [Crossref]

34. Baicu CF, Zile MR, Aurigemma GP, Gaasch WH (2005) Left ventricular systolic performance, function, and contractility in patients with diastolic heart failure. Circ 111: 2306-2312. [Crossref]

35. Yoshida T, Ohte N, Narita H, Sakata S, Wakami K, et al. (2006) Lack of inertia force of late systolic aortic flow is a cause of left ventricular isolated diastolic dysfunction in patients with coronary artery disease. J Am Coll Cardiol 48: 983-991. [Crossref]

36. Mosterd A, Hoes AW (2007) Clinical epidemiology of heart failure. Heart 93: 11371146. [Crossref]

37. Redfield MM, Jacobsen SJ, Burnett Jr JC, Mahoney DW, Bailey KR, et al. (2003) Burden of systolic and diastolic ventricular dysfunction in the community: appreciating the scope of the heart failure epidemic. Jama 289: 194-202. [Crossref]

38. Bleumink GS, Knetsch AM, Sturkenboom MC, Straus SM, Hofman A, et al. (2004) Quantifying the heart failure epidemic: prevalence, incidence rate, lifetime risk and prognosis of heart failure: the Rotterdam Study. Eur Heart J 25: 1614-1619. [Crossref]

39. Ceia F, Fonseca C, Mota T, Morais H, Matias F, et al. (2002) Prevalence of chronic heart failure in Southwestern Europe: the EPICA study. Eur J Heart Fail 4: 531-539. [Crossref]

40. Gerber Y, Weston SA, Redfield MM, Chamberlain AM, Manemann SM, et al. (2015) A contemporary appraisal of the heart failure epidemic in Olmsted County, Minnesota, 2000 to 2010. JAMA internal medicine 175: 996-1004. [Crossref]

41. Owan TE, Hodge DO, Herges RM, Jacobsen SJ, Roger VL, et al. (2006) Trends in prevalence and outcome of heart failure with preserved ejection fraction. $N$ Engl J Med 355: 251-259. [Crossref]

42. Van Riet EE, Hoes AW, Limburg A, Landman MA, van der Hoeven H, et al. (2014) Prevalence of unrecognized heart failure in older persons with shortness of breath on exertion. Eur J Heart Fail 16: 772-777. [Crossref]

43. Rutten FH, Cramer MJ, Grobbee DE, Sachs AP, Kirkels JH, et al. (2005) Unrecognized heart failure in elderly patients with stable chronic obstructive pulmonary disease. Eur Heart J 26: 1887-1894. [Crossref]

44. Abhayaratna WP, Smith WT, Becker NG, Marwick TH, Jeffery IM, et al. (2006) Prevalence of heart failure and systolic ventricular dysfunction in older Australians: the Canberra Heart Study. Med J Aust 184: 151-154. [Crossref]

45. Badano LP, Albanese MC, De Biaggio P, Rozbowsky P, Miani D, et al. (2004) Prevalence, clinical characteristics, quality of life, and prognosis of patients with congestive heart failure and isolated left ventricular diastolic dysfunction. $J$ Am Soc Echocardiogr 17: 253-261. [Crossref]

46. Hellermann JP, Jacobsen SJ, Reeder GS, Lopez-Jimenez F, Weston SA, et al. (2003) Heart failure after myocardial infarction: prevalence of preserved left ventricular systolic function in the community. Am Heart $J$ 145: 742-748. [Crossref]

47. Gomez-Soto FM, Andrey JL, Garcia-Egido AA, Escobar MA, Romero SP, et al. (2011) Incidence and mortality of heart failure: a community-based study. Int J Cardiol 151: 40-45. [Crossref]

48. Ohlmeier C, Mikolajczyk R, Frick J, Prütz F, Haverkamp W, et al. (2015) Incidence, prevalence and 1-year all-cause mortality of heart failure in Germany: a study based on electronic healthcare data of more than six million persons. Clin Res Cardiol 104 688-696. [Crossref]
49. Cohn JN, Johnson G (1990) Heart failure with normal ejection fraction. The V-HeFT Study. Veterans Administration Cooperative Study Group. Circ 81: III48-III53. [Crossref]

50. Masoudi FA, Havranek EP, Smith G, Fish RH, Steiner JF, et al. (2003) Gender, age, and heart failure with preserved left ventricular systolic function. $J$ Am Coll Cardiol 41: 217-223. [Crossref]

51. Vasan RS, Larson MG, Benjamin EJ, Evans JC, Reiss CK, et al. (1999) Congestive heart failure in subjects with normal versus reduced left ventricular ejection fraction: prevalence and mortality in a population-based cohort. J Am Coll Cardiol 33: 1948 1955. [Crossref]

52. Ghali JK, Kadakia S, Bhatt A, Cooper R, Liao Y (1992) Survival of heart failure patients with preserved versus impaired systolic function: the prognostic implication of blood pressure. Am Heart J 123: 993-997. [Crossref]

53. Aronow WS, Ahn C, Kronzon I (1990) Prognosis of congestive heart failure in elderly patients with normal versus abnormal left ventricular systolic function associated with coronary artery disease. Am J Cardiol 66: 1257-1259. [Crossref]

54. Taffet GE, Teasdale TA, Bleyer AJ, Kutka NJ, Luchi RJ (1992) Survival of elderly men with congestive heart failure. Age and Ageing 21: 49-55. [Crossref]

55. Warnowicz MA, Parker H, Cheitlin MD (1983) Prognosis of patients with acute pulmonary edema and normal ejection fraction after acute myocardial infarction. Circ 67: 330-334. [Crossref]

56. McAlister FA, Teo KK, Taher M, Montague TJ, Humen D, et al. (1999) Insights into the contemporary epidemiology and outpatient management of congestive heart failure. Am Heart J 138:87-94. [Crossref]

57. Tribouilloy C, Rusinaru D, Mahjoub H, Souliere V, Levy F, et al. (2007) Prognosis of heart failure with preserved ejection fraction: a 5 year prospective population-based study. Eur Heart J 29: 339-347. [Crossref]

58. Bhatia RS, Tu JV, Lee DS, Austin PC, Fang J, et al. (2006) Outcome of heart failure with preserved ejection fraction in a population-based study. $N$ Engl J Med 355: 260269. [Crossref]

59. Redfield MM (2016) Heart failure with preserved ejection fraction. N Engl J Med 375 1868-1877. [Crossref]

60. Lam CS, Roger VL, Rodeheffer RJ, Bursi F, Borlaug BA, et al. (2007) Cardiac structure and ventricular-vascular function in persons with heart failure and preserved ejection fraction from Olmsted County, Minnesota. Circ 115: 1982-1990. [Crossref]

61. Mohammed SF, Borlaug BA, Roger VL, Mirzoyev SA, Rodeheffer RJ, et al. (2012) Comorbidity and ventricular and vascular structure and function in heart failure with preserved ejection fraction: a community-based study. Circ-Heart Fail 5: 710-719. [Crossref]

62. Zile MR, Gottdiener JS, Hetzel SJ, McMurray JJ, Komajda M, et al. (2011) Prevalence and significance of alterations in cardiac structure and function in patients with heart failure and a preserved ejection fraction. Circ 124: 2491-2501. [Crossref]

63. Lam CS, Roger VL, Rodeheffer RJ, Borlaug BA, Enders FT, et al. (2009) Pulmonary hypertension in heart failure with preserved ejection fraction: a community-based study. J Am Coll Cardiol 53: 1119-1126. [Crossref]

64. Borlaug BA, Redfield MM, Melenovsky V, Kane GC, Karon BL, et al. (2013) Longitudinal changes in left ventricular stiffness: a community-based study. Circ-Heart Fail 6: 944-952. [Crossref]

65. Solomon SD, Janardhanan R, Verma A, Bourgoun M, Daley WL, et al. (2007) Effect of angiotensin receptor blockade and antihypertensive drugs on diastolic function in patients with hypertension and diastolic dysfunction: a randomised trial. The Lancet 369: 2079-2087. [Crossref]

66. Zile MR, Baicu CF, Gaasch WH (2004) Diastolic heart failure: abnormalities in active relaxation and passive stiffness of the left ventricle. N Engl J Med 350: 1953-1959. [Crossref]

67. Gladden JD, Linke WA, Redfield MM (2014) Heart failure with preserved ejection fraction. Pflügers Archiv-European Journal of Physiology 466: 1037-1053. [Crossref]

68. Sasayama S, Nonogi H, Miyazaki S, Sakurai T, Kawai C, Eiho S, Kuwahara M. Changes in diastolic properties of the regional myocardium during pacing-induced ischemia in human subjects. Am J Cardiol 5: 599-606. [Crossref]

69. Melenovsky V, Borlaug BA, Rosen B, Hay I, Ferruci L, et al. (2007) Cardiovascular features of heart failure with preserved ejection fraction versus nonfailing hypertensive left ventricular hypertrophy in the urban Baltimore community: the role of atrial remodeling/dysfunction. Am J Cardiol 49: 198-207. [Crossref] 
Albakri A (2018) Heart failure with preserved ejection fraction: A review of clinical status and meta-analysis of diagnosis by myocardial strain and effect of medication on mortality and hospitalization

70. Zakeri R, Chamberlain AM, Roger VL, Redfield MM (2013) Temporal relationship and prognostic significance of atrial fibrillation in heart failure patients with preserved ejection fraction: a community-based study. Circ. [Crossref]

71. Borlaug BA, Kass DA (2011) Ventricular-vascular interaction in heart failure. Cardiology clinics 29: 447-459. [Crossref]

72. Borlaug BA, Olson TP, Lam CS, Flood KS, Lerman A, et al. (2010) Global cardiovascular reserve dysfunction in heart failure with preserved ejection fraction. $J$ Am Coll Cardiol 56: 845-854. [Crossref]

73. Borlaug BA, Melenovsky V, Russell SD, Kessler K, Pacak K, et al. (2006) Impaired chronotropic and vasodilator reserves limit exercise capacity in patients with heart failure and a preserved ejection fraction. Circ 114: 2138-2147. [Crossref]

74. Guazzi M, Vicenzi M, Arena R, Guazzi MD (2011) Pulmonary hypertension in heart failure with preserved ejection fraction: a target of phosphodiesterase- 5 inhibition in a 1-year study. Circ. [Crossref]

75. Lund LH, Donal E, Oger E, Hage C, Persson H, et al. (2014) Association between cardiovascular vs. non-cardiovascular co-morbidities and outcomes in heart failure with preserved ejection fraction. Eur J Heart Fail 16: 992-1001. [Crossref]

76. Paulus WJ, Tschope C (2013) A novel paradigm for heart failure with preserved ejection fraction: comorbidities drive myocardial dysfunction and remodeling through coronary microvascular endothelial inflammation. J Am Coll Cardiol 62: 263-271. [Crossref]

77. Ather S, Chan W, Bozkurt B, Aguilar D, Ramasubbu K, et al. (2012) Impact of noncardiac comorbidities on morbidity and mortality in a predominantly male population with heart failure and preserved versus reduced ejection fraction. $J$ Am Coll Cardiol 59: 998-1005. [Crossref]

78. Lam CS, Lyass A, Kraigher-Krainer E, Massaro JM, Lee DS, et al. (2011) Cardiac dysfunction and noncardiac dysfunction as precursors of heart failure with reduced and preserved ejection fraction in the community. Circ 124: 24-30. [Crossref]

79. Haass M, Kitzman DW, Anand IS, Miller A, Zile MR, et al. (2011) Body mass index and adverse cardiovascular outcomes in heart failure patients with preserved ejection fraction: results from the Irbesartan in Heart Failure with Preserved Ejection Fraction (I-PRESERVE) trial. Circ-Heart Fail 4: 324-331. [Crossref]

80. Hummel SL, Seymour EM, Brook RD, Kolias TJ, Sheth SS, et al. (2012) Low-sodium dietary approaches to stop hypertension diet reduces blood pressure, arterial stiffness, and oxidative stress in hypertensive heart failure with preserved ejection fraction. Hypertens 60: 1200-1206. [Crossref]

81. Tian N, Moore RS, Braddy S, Rose RA, Gu JW, et al. (2007) Interactions between oxidative stress and inflammation in salt-sensitive hypertension. Am J Physiol Heart Circ Physiol 293: H3388-H3395. [Crossref]

82. Macdougall IC, Canaud B, de Francisco AL, Filippatos G, Ponikowski P, et al. (2012) Beyond the cardiorenal anaemia syndrome: recognizing the role of iron deficiency. Eur $J$ Heart Fail 14: 882-886. [Crossref]

83. Mohammed SF, Borlaug BA, Roger VL, Mirzoyev SA, Rodeheffer RJ, Cet al. (2012) Comorbidity and ventricular and vascular structure and function in heart failure with preserved ejection fraction: a community-based study. Circ-Heart Fail 5: 710-719. [Crossref]

84. Kalogeropoulos A, Georgiopoulou V, Psaty BM, Rodondi N, Smith AL, et al. (2012) Inflammatory markers and incident heart failure risk in older adults: the Health $\mathrm{ABC}$ (Health, Aging, and Body Composition) study. J Am Coll Cardiol 55: 2129-2137. [Crossref]

85. Collier P, Watson CJ, Voon V, Phelan D, Jan A, et al. (2011) Can emerging biomarkers of myocardial remodelling identify asymptomatic hypertensive patients at risk for diastolic dysfunction and diastolic heart failure? Eur J Heart Fail 13: 1087-1095. [Crossref]

86. Shah KB, Kop WJ, Christenson RH, Diercks DB, Henderson S, et al. (2011) Prognostic utility of ST2 in patients with acute dyspnea and preserved left ventricular ejection fraction. Clin Chem 57: 874-882. [Crossref]

87. Matsubara J, Sugiyama S, Nozaki T, Sugamura K, Konishi M, et al. (2011) Pentraxin 3 is a new inflammatory marker correlated with left ventricular diastolic dysfunction and heart failure with normal ejection fraction. $J$ Am Coll Cardiol 57: 861-869. [Crossref]

88. Westermann D, Lindner D, Kasner M, Zietsch C, Savvatis K, et al. (2011) Cardiac inflammation contributes to changes in the extracellular matrix in patients with heart failure and normal ejection fraction. Circ-Heart Fail 4: 44-52. [Crossref]

89. Shenouda SM, Widlansky ME, Chen K, Xu G, Holbrook M, et al. (2011) Altered mitochondrial dynamics contributes to endothelial dysfunction in diabetes mellitus. Circ 124: 444-453. [Crossref]
90. Rajapakse AG, Yepuri G, Carvas JM, Stein S, Matter CM, et al. (2011) Hyperactive S6K1 mediates oxidative stress and endothelial dysfunction in aging: inhibition by resveratrol. PloS one 6: e19237. [Crossref]

91. Tschope C, Bock CT, Kasner M, Noutsias M, Westermann D, et al. (2005) High prevalence of cardiac parvovirus B19 infection in patients with isolated left ventricular diastolic dysfunction. Circ 111: 879-886. [Crossref]

92. Van Heerebeek L, Hamdani N, Falcão-Pires I, Leite-Moreira AF, Begieneman MP, et al. (2012) Low myocardial protein kinase $\mathrm{G}$ activity in heart failure with preserved ejection fraction. Circ [Crossref]

93. Schulz E, Jansen T, Wenzel P, Daiber A, Münzel T. et al. (2008) Nitric oxide, tetrahydrobiopterin, oxidative stress, and endothelial dysfunction in hypertension. Antioxidants \& redox signaling 10: 1115-1126. [Crossref]

94. Solomon SD, Zile M, Pieske B, Voors A, Shah A, et al. (2012) The angiotensin receptor neprilysin inhibitor LCZ696 in heart failure with preserved ejection fraction: a phase 2 double-blind randomised controlled trial. The Lancet 380: 1387-1395. [Crossref]

95. Calderone A, Thaik CM, Takahashi N, Chang DL, Colucci WS (1998) Nitric oxide, atrial natriuretic peptide, and cyclic GMP inhibit the growth-promoting effects of norepinephrine in cardiac myocytes and fibroblasts. J Clin Invest 101: 812-818. [Crossref]

96. Takimoto E, Champion HC, Li M, Belardi D, Ren S, et al. (2005) Chronic inhibition of cyclic GMP phosphodiesterase 5A prevents and reverses cardiac hypertrophy. Nat Med 11: 214-222. [Crossref]

97. Isidori A, Giannetta E, Galea N, Iacopo C, Mandosi E, et al. (2012) Phosphodiesterase 5a Improves Diabetic Cardiomyopathy Exerting An Anti-remodeling Effect: A Randomized, Controlled Clinical Trial With Magnetic Resonance Imaging: ps-04-002. J Sex Med 9: 310. [Crossref]

98. Falcao-Pires I, Hamdani N, Borbély A, Gavina C, Schalkwijk CG, et al. (2011) Diabetes mellitus worsens diastolic left ventricular dysfunction in aortic stenosis through altered myocardial structure and cardiomyocyte stiffness. Circ 124: 1151-1159. [Crossref]

99. Selby DE, Palmer BM, LeWinter MM, Meyer M (2011) Tachycardia-induced diastolic dysfunction and resting tone in myocardium from patients with a normal ejection fraction. J Am Coll Cardiol 58: 147-154. [Crossref]

100. Matsubara BB, Matsubara LS, Zornoff LA, Franco M, Janicki JS (1998) Left ventricular adaptation to chronic pressure overload induced by inhibition of nitric oxide synthase in rats. Basic Res Cardiol 93: 173-181. [Crossref]

101. Borbely A, Falcao-Pires I, Van Heerebeek L, Hamdani N, Edes I, et al. (2009) Hypophosphorylation of the Stiff N2B titin isoform raises cardiomyocyte resting tension in failing human myocardium. Circ Res 104: 780-786. [Crossref]

102. Kasner M, Westermann D, Lopez B, Gaub R, Escher F, et al. (2011) Diastolic tissue Doppler indexes correlate with the degree of collagen expression and cross-linking in heart failure and normal ejection fraction. $J$ Am Coll Cardiol 57: 977-985. [Crossref]

103. Gazewood J, Turner PL (2017) Heart Failure with Preserved Ejection Fraction Diagnosis and Management. Am Fam Physician 96: 582-588. [Crossref]

104. Pellicori P, Cleland JG (2014) Heart failure with preserved ejection fraction. Clin Med 14(Suppl 6), s22-s28. [Crossref]

105. Uandinov L, Eberli FR, Seiler C (1998) European Study Group on Dias-tolic Heart Failure. How to diagnose diastolic heart failure (J). Eur Heart $J$ 19: 990-1003. [Crossref]

106. Vasan RS, Levy D (2000) Defining diastolic heart failure: a call for standardized diagnostic criteria. Circ 101: 2118-2121. [Crossref]

107. Yturralde RF, Gaasch WH (2005) Diagnostic criteria for diastolic heart failure. Prog Cardiovasc Dis 47: 314-319. [Crossref]

108. Ponikowski P, Voors AA, Anker SD, Bueno H, Cleland JG, et al. (2016) 2016 ESC Guidelines for the diagnosis and treatment of acute and chronic heart failure: The Task Force for the diagnosis and treatment of acute and chronic heart failure of the European Society of Cardiology (ESC) Developed with the special contribution of the Heart Failure Association (HFA) of the ESC. Eur Heart J 37: 2129-2200. [Crossref]

109. MacIver DH, Adeniran I, Zhang H (2015) Left ventricular ejection fraction is determined by both global myocardial strain and wall thickness. IJC Heart \& Vasculature 7: 113-118[Crossref]

110. Wang J, Khoury DS, Yue Y, Torre-Amione G, Nagueh SF (2008) Preserved lef ventricular twist and circumferential deformation, but depressed longitudinal and radial deformation in patients with diastolic heart failure. Eur Heart J 29: 1283-1289. [Crossref] 
Albakri A (2018) Heart failure with preserved ejection fraction: A review of clinical status and meta-analysis of diagnosis by myocardial strain and effect of medication on mortality and hospitalization

111. Liu YW, Tsai WC, Su CT, Lin CC, Chen JH (2009) Evidence of left ventricular systolic dysfunction detected by automated function imaging in patients with heart failure and preserved left ventricular ejection fraction. J Card Fail 15: 782-789. [Crossref]

112. Phan TT, Shivu GN, Abozguia K, Gnanadevan M, Ahmed I, et al. (2009) Left ventricular torsion and strain patterns in heart failure with normal ejection fraction are similar to age-related changes. Eur J Echocardiogr 10: 793-800. [Crossref]

113. Tan YT, Wenzelburger F, Lee E, Heatlie G, Leyva F, et al. (2009) The pathophysiology of heart failure with normal ejection fraction: exercise echocardiography reveals complex abnormalities of both systolic and diastolic ventricular function involving torsion, untwist, and longitudinal motion. J Am Coll Cardiol 54: 36-46. [Crossref]

114. Yip GW, Zhang Q, Xie JM, Liang YJ, Liu YM, et al. (2011) Resting global and regional left ventricular contractility in patients with heart failure and normal ejection fraction: insights from speckle-tracking echocardiography. Heart, 97(4), 287-294. [Crossref]

115. Kraigher-Krainer E, Shah AM, Gupta DK, Santos A, Claggett B, et al. (2014) Impaired systolic function by strain imaging in heart failure with preserved ejection fraction. J Am Coll Cardiol 63: 447-456. [Crossref]

116. Luo XX, Fang F, Lee AP, Sun JP, Li S, et al. (2014) What can three-dimensional speckle-tracking echocardiography contribute to evaluate global left ventricular systolic performance in patients with heart failure? Int J Cardiol 172: 132-137. [Crossref]

117. Menet A, Greffe L, Ennezat PV, Delelis F, Guyomar Y, et al (2014) Is mechanical dyssynchrony a therapeutic target in heart failure with preserved ejection fraction? Am Heart J 168: 909-916. [Crossref]

118. Pellicori P, Kallvikbacka-Bennett A, Khaleva O, Carubelli V, Costanzo P, et al. (2014) Global longitudinal strain in patients with suspected heart failure and a norma ejection fraction: does it improve diagnosis and risk stratification? Int J Card Imaging 30: 69-79. [Crossref]

119. Toufan M, Gharebaghi SM, Pourafkari L, Abdolahinia ED (2015) Systolic longitudinal function of the left ventricle assessed by speckle tracking in heart failure patients with preserved ejection fraction. J Tehran Heart Cent 10: 194-200. [Crossref]

120. Carluccio E, Biagioli P, Zuchi C, Bardelli G, Murrone A, et al. (2016) Fibrosis assessment by integrated backscatter and its relationship with longitudinal deformation and diastolic function in heart failure with preserved ejection fraction. Int J Card Imaging 32: 1071-1080. [Crossref]

121. Bosch L, Lam CS, Gong L, Chan SP, Sim D, et al. (2017) Right ventricular dysfunction in left-sided heart failure with preserved versus reduced ejection fraction. Eur J Heart Fail 19: 1664-1671. [Crossref]

122. Huang W, Chai SC, Lee SG, MacDonald MR, Leong KT (2017) Prognostic factors after index hospitalization for heart failure with preserved ejection fraction. $\mathrm{Am} \mathrm{J}$ Cardiol 119: 2017-2020. [Crossref]

123. Maggioni AP, Anker SD, Dahlström U, Filippatos G, Ponikowski P, et al. (2013) Are hospitalized or ambulatory patients with heart failure treated in accordance with European Society of Cardiology guidelines? Evidence from 12440 patients of the ESC Heart Failure Long-Term Registry. Eur J Heart Fail 15: 1173-1184. [Crossref]

124. Pitt B, Pfeffer MA, Assmann SF, Boineau R, Anand IS, et al. (2014) Spironolactone for heart failure with preserved ejection fraction. N Engl J Med 370: 1383-1392. [Crossref]

125. Redfield MM, Chen HH, Borlaug BA, Semigran MJ, Lee KL, et al, (2013) Effect of phosphodiesterase-5 inhibition on exercise capacity and clinical status in heart failure with preserved ejection fraction: a randomized clinical trial. Jama 309: 1268-1277. [Crossref]

126. Beckett NS, Peters R, Fletcher AE, Staessen JA, Liu L, et al. (2008) Treatment of hypertension in patients 80 years of age or older. $N$ Engl J Med 358: 1887-1898. [Crossref]

127. Fukuta H, Goto T, Wakami K, Ohte N (2016) Effects of drug and exercise intervention on functional capacity and quality of life in heart failure with preserved ejection fraction: a meta-analysis of randomized controlled trials. Eur J Prev Cardiol 23: 7885. [Crossref]

128. Flather MD, Shibata MC, Coats AJ, Van Veldhuisen DJ, Parkhomenko A, et al. (2005) Randomized trial to determine the effect of nebivolol on mortality and cardiovascular hospital admission in elderly patients with heart failure (SENIORS). Eur Heart J 26: 215-225. [Crossref]

129. Ahmed A, Rich MW, Fleg JL, Zile MR, Young JB, et al. (2006) Effects of digoxin on morbidity and mortality in diastolic heart failure: the ancillary digitalis investigation group trial. Circ 114: 397-403. [Crossref]
130. Cleland JG, Tendera M, Adamus J, Freemantle N, Polonski L, et al. (2006) The perindopril in elderly people with chronic heart failure (PEP-CHF) study. Eur Heart $J$ 27: 2338-2245. [Crossref]

131. Dobre D, van Veldhuisen DJ, DeJongste MJ, Lucas C, Cleuren G, et al. (2007) Prescription of beta-blockers in patients with advanced heart failure and preserved left ventricular ejection fraction. Clinical implications and survival. Eur J Heart Fail 9: 280-286. [Crossref]

132. Yip GW, Wang M, Wang T, Chan S, Fung JW, et al. (2008) The Hong Kong Diastolic Heart Failure Study: a Randomized Control Trial of Diuretics, Irbesartan and Ramipril on Quality of Life, Exercise Capacity, Left Ventricular Global and Regional Function in Heart Failure With a Normal Ejection Fraction. Heart 94: 573-580. [Crossref]

133. Van Veldhuisen DJ, Cohen-Solal A, Böhm M, Anker SD, Babalis D, et al. (2009) Beta-blockade with nebivolol in elderly heart failure patients with impaired and preserved left ventricular ejection fraction: Data From SENIORS (Study of Effects of Nebivolol Intervention on Outcomes and Rehospitalization in Seniors With Heart Failure). J Am Coll Cardiol 53: 2150-2158. [Crossref]

134. Mulder BA, Van Veldhuisen DJ, Crijns HJ, Böhm M, Cohen-Solal A, et al. (2012) Effect of nebivolol on outcome in elderly patients with heart failure and atria fibrillation: insights from SENIORS. Eur J Heart Fail 14: 1171-1178. [Crossref]

135. Nevzorov R, Porath A, Henkin Y, Kobal SL, Jotkowitz A, et al. (2012) Novack V. Effect of beta blocker therapy on survival of patients with heart failure and preserved systolic function following hospitalization with acute decompensated heart failure. Eur J Intern Med 23: 374-378. [Crossref]

136. Yamamoto K, Origasa H, Hori M, J-DHF Investigators (2013) Effects of carvedilo on heart failure with preserved ejection fraction: the Japanese Diastolic Heart Failure Study (J-DHF). Eur J Heart Fail 15: 110-118. [Crossref]

137. Holland DJ, Kumbhani DJ, Ahmed SH, Marwick TH (2011) Effects of treatment on exercise tolerance, cardiac function, and mortality in heart failure with preserved ejection fraction: a meta-analysis. J Am Coll Cardiol 57: 1676-1686. [Crossre ref]

138. Zheng SL, Chan FT, Nabeebaccus AA, Shah AM, McDonagh T, et al. (2017) Drug treatment effects on outcomes in heart failure with preserved ejection fraction: a systematic review and meta-analysis. Heart 104: 407-415. [Crossref]

139. Meta-analysis Global Group in Chronic Heart Failure (MAGGIC) (2011). The survival of patients with heart failure with preserved or reduced left ventricular ejection fraction: an individual patient data meta-analysis. Eur Heart $J$ 33: 17501757. [Crossref]

Copyright: (C)2018 Albakri A. This is an open-access article distributed under the terms of the Creative Commons Attribution License, which permits unrestricted use, distribution, and reproduction in any medium, provided the original author and source are credited. 